\title{
External stakeholders and Health Promoting Schools: complexity and practice in South Africa
}

Rika Preiser, Patricia Struthers, Suraya Mohamed, Neil Cameron, Estelle Lawrence

\section{Abstract \\ Purpose}

This paper examines the role of two higher education institutions in the Western Cape, South Africa, and how their initiatives and collaboration brought about a particular Health Promoting Schools (HPS) program in a resource poor setting. The aim of this paper is to reflect on the importance of the role that external systemic actors and stakeholders can play in the process of designing and implementing HPS programs in resource poor settings.

\section{Design/methodology/approach}

In this paper a complex systems approach is employed to describe two different participatory methods of engagement with HPS by higher education institutions. On the one hand, engagement took place in terms of a formal and funded project, directed at the organizational level of the school, with capacity building as its aim. On the other hand, engagement was initiated informally (as part of a service learning project) via collaboration with the formal project, directed at the individual level of learners in the school.

\section{Findings}

In recognizing the complex nature of planning and implementing HPS programs, the paper demonstrates that HPS approaches could benefit from engaging with resources outside the ambit of institutional health and educational policies and structures.

\section{Originality/value}

By acknowledging the systemic nature of implementing HPS strategies, novel collaborations emerge as a result. The paper highlights the important role that external stakeholders such as higher education institutions play in creating and sustaining tailor-made HPS programs for schools based in resource poor settings.

\section{Introduction}

Traditionally Health Promoting School (HPS) initiatives are developed and implemented by people working in and with governmental health and education departments (Moon et al. 1999; Young 2005). These interventions are planned from an institutional level and executed within the framework that the structural policies and legislation allow and prescribe. One of the central insights from a position that acknowledges organizational complexity suggests that conventional patterns of topdown problem-solving methods are to be revised (Baric 1994). Viewing social 
systems such as health and education systems (e.g. schools) (Kremser 2010; Keshavarz et al. 2010) through the research paradigm of complexity theory introduces a conceptual shift in the way we engage with and plan health promoting strategies (Rowling and Jeffreys 2006).

Moreover, the study of complex phenomena suggests a shift in focus in terms of how research projects are implemented and to what extent intervention strategies are challenged to consider the implications of complexity. The reason being, that complexity is a characteristic of a system and is not to be found in any one of its components (Cilliers 1998). This shift of focus implies that complex systems are not to be considered in isolation but as relationally constituted. Hence, projects and intervention strategies aimed at bringing about social change (such as healthier schools and communities) cannot be effectively implemented as "one-size-fits-all" kits (Preiser and Cilliers 2010: 281). Complex systems are radically open and evolving in the context in which they exist (Chu et al. 2003). Radical openness implies that there are rich and dynamic connections between systems and their environments, which are generators of complexity (Morin 2008). Interventions in schools can thus never happen in isolation and can only be effective when important connections to resources in the environment (such as external role players) are considered as vital elements that could bring about social change.

A paradigm such as the "eco-holistic" systems approach (Mukoma and Flisher 2004: 357) acknowledges that schools, the health system and communities that they serve are constituted as complex systems and proposes that health promotion can be identified as a systemic property that is not located in the isolated components of the system, but emerges from the dynamic interactions between components, systems, and their environments (Cilliers 1998; Thrift 1999). Subsequently, the outcome of a specific HPS intervention should be regarded as an emergent property that comes about as a result of the dynamic and rich interactions between various role players in the system and its environment. From this perspective, it is clear that it is problematic to offer descriptions of interventional programs that formalize notions of capacity building, development or social change in terms of quantitative sets of data or linear equations. Intervention strategies are viewed as processes of learning in themselves and methodologies are more heuristic than programmatic and are sensitive to how the system under observation responds to certain strategies and actions (Litaker and Tomolo et al. 2006).

Another generator of complexity in especially lower socio-economic areas in South Africa, is the high prevalence of the TB-HIV epidemic in South Africa (Robins 2006; Den Boon and van Lill et al. 2007). As the TB-HIV epidemic grew, those involved in health promotion projects were compelled to take into account the multi-faceted underlying determinants of HIV and TB such as unemployment, migrancy and disrupted families, uninspiring schools, poverty and malnutrition. This paper discusses an HPS approach that attempted to acknowledge the complex and systemic 
nature of the TB-HIV epidemic and the role it played in implementing an HPS project. In recognizing the complex nature of planning and implementing HPS programs in lower socio-economic settings in South Africa, project coordinators are obliged to look for resources outside the ambit of institutional health and educational policies and initiatives (Aldinger et al. 2008; Dooris 2012). In resource poor settings vital inputs can be found in the dynamic interactions with a variety of stakeholders in the area served by the school or within the contextual environment of the school. As Inchley et al. (2007) recognized, various ways of collaboration form an important factor in HPS participation, which should include working with external bodies, pupils and parents. Hence, this paper reflects on the role that external systemic actors and stakeholders can play in the process of designing and implementing health promoting programs in such settings. Unfortunately there is not much HPS literature to draw on conceptually or to compare this project with. In light of the lack of literature sources, this paper examines the role of two higher education institutions in the Western Cape, South Africa, and how their initiatives and collaboration as external role players undertook an HPS program in a resource poor setting. The focus of this paper is not to describe the methodology and process of the project in detail (this has been done elsewhere-see Struthers 2012 and UWC 2012). Instead, this paper will focus on the lessons learnt about the involvement of external stakeholders and specifically about the role of higher education institutions in an HPS project collaboration between the University of the Western Cape (UWC) and the Stellenbosch University (SU) (both located in the Western Cape, South Africa).

\section{Background}

In South Africa generally, school health is seen as a responsibility shared by the Departments of Health and Education (Department of Health 2012). School health commonly follows a top-down approach that relies on centralized organizational structures while the HPS approach calls for more decentralization and participation so that both the complexity and context of each individual school are taken into account (Rowling and Jeffreys 2000). This paper discusses an example of where the implementation of the HPS approach at a designated high school (in this paper we will refer to this school as 'School A') in the Western Cape relied strongly on the engagement and collaboration of both external and internal actors to develop and implement a new HPS program. Through partnership and collaborative strategies actors at two higher education institutions emerged to be appropriate sources of action and social change.

Located in close proximity to School A, the University of the Western Cape (UWC) and the Stellenbosch University (SU) employed different strategies with which to develop and support one HPS initiative. UWC started the HPS Project, which was directed at the organizational level of the school aiming to build the capacity of teachers and pupils in order to develop a sustainable HPS program at the school. The Community Health Division at the SU was looking for an opportunity for senior medical students to engage in a HPS project in order to encourage healthy habits in 
young people and develop long-term personal insights in health promotion and skills. Through collaboration in the wider UWC HPS project SU medical students were given the opportunity to work on a series of health promotion projects with the pupils and the life orientation teacher. The UWC academics, who had been working for some time with teachers and parents at the school, facilitated the process.

\section{The context of school A}

Viewed through the lens of complexity, external and historical systemic determinants constitute important contextual components that shape the health of a school community system. One important determinant in the case of School A is its historical context. During the apartheid era in South Africa, the Group Areas Act of 1950 (Republic of South Africa 1950) officially designated people according to one of four population groups. The community, in which School A was located, was classified as "coloured"i and as a result people were relocated to a different neighbourhood as prescribed by the authorities of the time.

Consequently School A was moved from the northern to the southern side of the railway line in 1964 with teachers and pupils having to carry desks, tables and cupboards to the new premises about 5 kilometers away. The relocated school was situated in an area where people were poorer and the school became a target for burglaries and vandalism. Despite or because of all these difficulties, the teachers were dedicated to fostering a culture of learning and to give the pupils opportunities to overcome the difficult circumstances by being equipped with a solid education. Many pupils excelled and the school developed a reputation for excellence, with numerous school leavers going on to become teachers, doctors, dentists, lawyers, ministers of religion, school principals and later to hold senior positions in government.

After the end of apartheid in 1994, many better-off families moved out of the area, which inevitably affected the social capital of the community feeding the school. Once again School A was faced with new challenges to survive in a community with increased unemployment, gangsterism, drug and alcohol abuse, teenage pregnancy and TB. The area had been identified as having one of the highest TB prevalence rates in South Africa (den Boon and van Lill et al. 2007). Currently few parents are involved in the school and many are unemployed so that the school governing body cannot raise money for extra teaching posts, leading to the teachers being overstretched. Academically the school tends to perform poorly with low literacy and numeracy skills (Western Cape Education Department 2011).

\section{Methodology}

This paper provides an example of how the acknowledgment of complexity in the implementation of HPS challenges traditional approaches to school health, by including external actors as important sources of action for the development of HPS projects. In this section we explore two different participatory methods of interaction 
between higher education institutions and School A, an HPS in the Western Cape. Information for this paper was sourced from the notes of the action reflection processes of the UWC HPS project team; the medical students' evaluations after their stints at the school and an interview with the teacher who was responsible for facilitating all the external roleplayers' HPS engagements at School A. The collaboration of universities with schools has been shown to be a beneficial reciprocal learning process for both parties (Dumka et al. 2007; Falter et al. 2011).

\section{The University of the Western Cape: Building HPS Capacity}

In response to the dual epidemics of HIV and TB in South Africa, the HPS Project of UWC obtained funding from Centres for Disease Control / President's Emergency Fund for AIDS Relief (CDC / PEPFAR), to develop a cluster of three high schools as health promoting schools in 2008 (UWC Centre for Research in HIV and AIDS 2010). The goal of the project was to build human and organizational capacity in order to reduce the spread of HIV and TB. School A was invited to become an HPS partner in this UWC HPS Project. Participation by School A was voluntary, but because of the project's focus on TB, School A was very willing to participate, as there is a very high TB infection rate in the area that the school serves. Over a three-year period many activities took place involving the three high schools using a variety of strategies and involving different stakeholders (Struthers, 2012; UWC HPS Project, 2012). Teachers, pupils and parents in each school identified current resources in their school and community; identified problems they experienced; and created a 'dream tree' of what was needed to be a health promoting school. The World Health Organization framework for HPS was used including developing healthy skills, healthy school policies, a healthy physical and psychosocial environment, strong links with the community and a partnership with external stakeholders. In addition self-care was considered an essential component.

Information on TB and HIV were provided using creative interactive approaches such as drama, role plays and explored in relation to their social determinants. Workshops included 'Gender and HIV', 'Understanding the HPS' using photovoice and metaphors (Sonn et al. 2011), 'Teacher Well-being', and 'Developing a School TB Policy'. Other strategies, which funding allowed, were annual 4-day leadership and empowerment camps for pupils and a 3 -day retreat for teachers.

In the process of developing action competence, teams of pupils and teachers, in each school and across schools, planned, implemented and reflected on activities such as a march through the community to raise awareness of TB and an interschool soccer tournament. Other outcomes included school feeding schemes, recycling projects and a first aid room.

Support was given to the schools by the UWC HPS Project through regular mentoring of the lead teacher and meetings of the active pupils and teachers. The Project signed a memorandum of understanding with the education district to 
promote a supportive partnership. Additionally, support was organized by facilitating the placement of university students in the schools, including occupational therapy students in two of the schools and SU medical students in School A.

An action-reflection process was used by the Project in planning. Reflections on the outcomes of the UWC HPS Project indicate capacity development has occurred on an individual level among pupils and teachers. However, change in the schools at an organizational level needs more time to evaluate. Additionally the large number of different activities and multiple intervening factors make it difficult to attribute a particular outcome to one activity, including the interventions by the medical students.

The University of Stellenbosch: medical students, community engagement and HPS Involving undergraduate students in service-learning is increasingly being used to train practitioners that are able to address the current and future needs of society (Hood 2009). Service-learning provides students with a "real world scenario in which to learn and grow" (Falter et al 2011:5).

Student medical interns at Stellenbosch University in the last 18 months of their sixyear course are allocated in small service-learning groups of two to four, to work at various community health centers for periods of five weeks. One of their tasks was to initiate a health promotion project on which they were assessed (the assessment was done by means of group presentations and project protocols for which students received marks). While many of these projects involved some degree of servicelearning and community engagement, medical students had increasingly expressed the desire to be part of a project with more apparent long-term value. Public Health lecturers at the SU contacted the project leader of UWC's HPS project about the possibility to allow students the opportunity to understand the HPS approach and what it means for a doctor to be involved in a community. The idea to collaborate with the SU was taken up favourably with the UWC project leader and the personnel of School A and a partnership started in which senior medical students of the SU would be part of the HPS Project of UWC at School A. During 2011 four groups of two to four SU students worked with supervisors from the two universities, the life orientation teacher and the HPS pupils at School A.

The first group did a survey of the HPS project and noted the resource constraints at the school and the limited involvement and understanding of HPS at the school as a whole. The second group ran a first aid course, which included cardio-pulmonary resuscitation on manikins from the medical school skills laboratory and found funding for a new first aid kit for the school. The following group facilitated a promotion event around world TB Day involving the whole school. The fourth group tested a recently developed TB and HIV workbook aimed at encouraging appropriate responses by teachers and pupils to prevention, early diagnosis and treatment (Struthers et al. 2011). 
Students reported during their group presentations that "We appreciated the opportunity to be part of an ongoing project. We learnt to use the available resources. Sometimes simple interventions and practical demonstrations are the most effective method."

"We also learnt how to use literature to give us ideas of what other people have tried in similar projects. And we learnt the importance of effective communication, to speak to the 'right' people to access resources. The project helped me to better understand the value health promotion especially in a school environment. In future though I would like to make more use of resources in the community."

"We piloted the new material on TB produced by the UWC project and provided feedback to Prof. Struthers and how to organize and pitch the lessons and activities to improve the effectiveness of the communication."

Pupils reported that TB projects gave them more confidence to talk about TB to family and friends and that the first aid project opened their eyes to the opportunites for acquiring skills not included in the curriculum.

However, the school health doctor (who was part of the Project team) was concerned that, "the students didn't get the opportunity to engage with school policy development and implementation or with the outside community or other support services and the multiple stakeholders. This was due to the short time they could spend at the school and the input and guidance they received. The school itself was also struggling to incorporate the principles of HPS themselves. Pass rates are a priority; HIV-TB was on our agenda, but not theirs."

The HPS teacher in School A said that the involvement of the medical students was beneficial for pupils and teachers however; the short rotation intervals compromised the continuity of the program. "Having the medical students here worked well, but having different groups for a few weeks at a time was disruptive. It would be better to have the same small group of students over a longer period... the HPS pupils really enjoyed the first aid classes... and I learnt a lot about TB and how to explain TB to the pupils."

\section{Discussion}

It has been argued that the involvement of external actors does not result in sustainable HPS projects, seeing that they discontinue their engagement when funding dries up (Mukoma and Flisher 2004). However, from the above it has been shown that external actors such as the UWC HPS Project team can be important sources of action in securing the initial implementation and sustainable development of HPS projects (Beautement and Broenner 2011). This study shows that resources in schooling communities are diverse and rich and that intersectoral collaboration can equip stakeholders to take hold of the process of becoming HPS themselves by combining efforts on different levels of engagement. 
Although the goal of the UWC HPS Project was to reduce the spread of TB and HIV, the underlying hypotheses for developing the cluster of high schools as health promoting schools was that by using the settings approach the supportive environment would make it easier for the school community, including pupils, teachers and families to make informed healthy choices. A systemic approach was used in the school, whereby the social determinants of the TB and HIV were acknowledged. This approach was supported by utilizing all the WHO health promotion action areas (World Health Organization, WHO 1986) including a selfcare component.

The partnership between the UWC HPS project and School A grew over a period as trust was built and teachers and pupils experienced personal development, which was beneficial to the school. The medical students were accepted into the school because of the trusting relationship between the school and the UWC HPS project. A reciprocal relationship developed between all parties involved. Both the external actors as well as School A benefited from this interaction. The partnership between the universities grew out of a shared interest in health promoting schools. There was a personal commitment from individuals at both institutions to ensure that the medical students would achieve their academic objectives while engaging closely with the community and that the school, including both pupils and teachers, would find the experience beneficial. Consequently many hours of personal time were given to the success of the project. There was, additionally, an unspoken hope that the medical students would recognize the transformative possibilities of HPS and be 'infected' with some of the passion experienced by the project organizers for continuing the work. Despite this, the medical students indicated that they felt lost in the school, outside of the traditional health setting. Their roles were no longer clear and their relationships with the teachers and pupils needed developing. Each new group needed to find their feet and establish a relationship.

Having external funding facilitated the organization of creative interactive activities involving multiple outside stakeholders at the schools and, at times, enabled the pupils and teachers to be in safer, youth friendly environments. It financed the production of the TB and HIV workbook that the medical students used (Struthers et al. 2011).

The use of an action-reflection process for planning, monitoring and evaluating the process and outcomes has allowed for individual activities to be considered within the context and allowed the students to interact with the various role players to plan and implement and build on the experience and reflection of the previous student groups. Plans often had to be adapted to fit the constraints of working in an unfamiliar school environment, especially as the students also had to complete a set of clinical learning activities at the local Community Health Center and another project on patients with physical impairments. Students also had to present these 
projects to a larger group of their peers. Even if the experience of the system as a whole was limited, the students did gain some insight into promoting healthy behavior in a settings approach. It would be a loss if future doctors only experience health promotion as an educational activity. HPS projects can provide medical students with an in-depth learning experience and encourage an approach of community engagement that goes beyond education to advocating for healthy school policies and environments and so strengthen the health promotion work of the health sector.

Given the short time of participation, it was difficult for the medical students to become immersed in the bigger project with the restricted time available to them. This made it unrealistic for them to experience the work that was being done on a systemic level. They would experience 'snapshots' of the bigger project and of the school context. While one group experienced the excitement of the new school year, the next group experienced the anxieties of pupils and teachers preparing for exams. The students were unable to take into account these contextual changes when evaluating their activities.

Another challenge was the contact time students were allowed to have with pupils. It was limited both by the education authorities and by the school principal in order not to detract negatively on academic activities. Perhaps the most important outcome was the increased understanding of the teacher about TB and ideas on how to share this information with the pupils suggesting that medical students could well play a valuable role in assisting the teachers. The parents or members of the community are another group that the medical students could reach through the schools without disrupting the time that the pupils spend on the set academic curriculum. This would also facilitate the development of the school as an HPS. Medical students may not be able to appreciate fully this systemic change as they are there for such a short time. Nevertheless, the insights that students gain by being actively involved in such a project should not be underestimated.

\section{Lessons learnt}

The key lessons learnt from this project proved that involving medical students in a bigger HPS project has the potential to be extremely beneficial provided:

1. That the university allocates an appropriate weighting to health promotion in the curriculum in order for the students to have the time and incentives to engage more fully with a school community using a settings approach;

2. Their involvement is systematically thought through with all key role players, including personnel from the medical school, from the bigger project, and from the school itself;

3. That a memorandum of understanding is agreed to by all parties to clarify roles and responsibilities and more clearly understand the benefits; 
4. That there is a small coordinating group at the school that includes pupils and teachers, with a clear mandate and who are committed to regular involvement over a period of about three to six months in the middle of the school year;

5. That medical students as far as possible work in partnership with teacher and/or parent groups;

6. That a participatory action research process is used;

7. There is recognition by all parties that the development of the school as an HPS is a complex interactive emerging process that requires time and commitment for this long term change.

\section{Conclusion}

Drawing on the characteristics of complex systems (Cilliers 1998), health promotion cannot be programmed to come about as a result of linear and institutional prescriptions. Instead, it emerges as a result of the interactions between non-linear components in complex systems. Utilizing resources from external actors and not only depending on institutional structures such as the formal policies of health and educational departments, encourages HPS to develop with more synergy and innovation.

External components influence the systemic organization of interventions in ways that are creative and unpredictable, but of incalculable importance. The role of external stakeholders is primarily that of intermediaries who often have exceptional capacities to negotiate partnerships and favorable conditions for primary stakeholders to establish sustainable health promoting initiatives even in difficult and challenging settings. 


\section{Bibliography}

Aldinger, C., Zhang, X.W., Liu, L.Q., Guo, J.X., Yu, S.H., Jones, J. (2008). "Strategies for implementing health promoting schools in a province in China", Promotion and Education, Vol. 15 No.1, pp. 24-29.

Baric, L. (1994), Health Promotion and Health Education in Practice. The Organizational Model. Altrincham, UK: Barns Publications.

Beautement, P., and Broenner, C. (2011), "Outcomes from the workshop 'Putting Complexity to Work-Supporting the Practitioners': implications for health care", Journal of Evaluation in Clinical Practice, Vol.18, pp. 190-194.

Chu, D., Strand, R., Fjelland, R. (2003), "Theories of complexity. Common denominators of complex systems", Complexity, Vol. 8 No. 3, pp. 19-30.

Cilliers, P. (1998), Complexity and Postmodernism: Understanding Complex Systems. London: Routledge.

Den Boon, S., van Lill, S.W.P., Borgdorff, M.W., Enarson, D.A., Verver, S., Bateman, E. D., Irusen, E., Lombard,C.J., White, N.W., de Villiers, C., Beyers, N. (2007), "High prevalence of tuberculosis in previously treated patients in Cape Town, South Africa", Emerging Infectious Diseases, Vol. 13 No.8, pp. 1189-1194.

Department of Health and Department of Basic Education (2012), Integrated School Health Policy. Online: http://www.doh.gov.za/docs/policy/2012/Integrated School Health Polic y.pdf. [Retrieved 15 January 2013].

Dooris, M. (2012), "Expert voices for change: Bridging the silos-towards healthy and sustainable settings for the $21^{\text {st }}$ century", Health and Place, Vol. 20, pp. 39-50.

Dumka, L.E., Mauricio, A.M., Gonzales, N.A. (2007), "Research partnerships with schools to implement

prevention programs for Mexican origin families”, Journal of Primary Prevention, Vol. 28, pp. 403-420.

Falter, R.A., Pignotti-Dumas, K., Popish, S. J., Petrelli, H.M.W., Best, M.A., Wilkinson, J.J. (2011), "A service-learning program in providing nutrition education to children", American Journal of Pharmaceutical Education, Vol. 75 No. 5 , article 85, pp. $1-7$.

Hood, JG. (2009), "Service-learning in dental education: meeting needs and challenges", Journal of Dental Education, Vol. 73 No. 4, pp., 454-463.

Inchley, J., Muldoon, J., Currie, C. (2007), "Becoming a health promoting school: evaluating the process of effective implementation in Scotland", Health Promotion International, Vol. 22 No. 1, pp. 65-71.

Keshavarz, N., Nutbeam, D., Rowling, L., Khavarpour, F. (2010), "Schools as social complex adaptive systems: A new way to understand the challenges of introducing the health promoting schools concept", Social Science \& Medicine, Vol. 70, pp. 1467-1474. 
Kremser, W. (2010), "Phases of school health promotion implementation through the lens of complexity theory: lessons learnt from an Austrian case study", Health Promotion International, Vol. 26 No. 2, pp. 136-146.

Litaker, D., Tomolo, A., Liberatore, V., Stange, K.C., Aron, D. (2006), "Using Complexity Theory to Build Interventions that Improve Health Care Delivery in Primary Care", Journal of General Internal Medicine, February, Vol. 21 (Suppl 2): 30-34.

Moon A., Mullee, M., Rogers, L. Thompson, R. L., Speller,V., Roderick, P. (1999), "Helping schools to become health-promoting environments - an evaluation of the Wessex Healthy Schools Award", Health Promotion International, Vol. 14 No. 2, pp. 111-122.

Morin, E. (2008), On Complexity, Cresskill: Hampton Press.

Mukoma, W., and Flisher, A. (2004), "Evaluations of health promoting schools: a review of nine studies", Health Promotion International, Vol. 19 No. 3, pp. $357-368$.

Preiser, R. and Cilliers, P. (2010), "Unpacking the ethics of complexity: concluding reflections", In Cilliers, P. and Preiser, R. (eds.), Complexity, Difference and Identity, London, New York: Springer, pp. 265-287.

Republic of South Africa. (1950), Group Areas Act (Act No. 41 of 1950), Government of the Republic of South Africa, Pretoria.

Robins, S. (2006), "From "Rights" to "Ritual": AIDS Activism in South Africa", American Anthropologist, Vol. 108 No. 2, pp. 312-323.

Rowling, L., and Jeffreys, V. (2006), "Capturing complexity: integrating health and education research to inform health-promoting schools policy and practice', Health Educ. Res, Vol. 21 No. 5, pp. 705-718.

Rowling, L., and Jeffreys, V. (2000), "Challenges in monitoring the development of health promoting schools", Health Education, Vol. 100, pp. 117-23.

Sonn, B., Santens, A., Ravau, S. (2011), "Hearing Learner Voice in health promoting schools through participatory action research", Perspectives in Education, Vol. 29 No. 1, pp. 93-104.

Statistics South Africa (Stats SA) (2011), Mid-year population estimates 2011. Online: $\quad$ http://www.statssa.gov.za/publications/Po302/P03022011.pdf [Retrieved 15 January, 2013].

Struthers, P., Rooth, E., Sylvester, A., Christoffels, A. (2011), How to be a Health Activist: a life skills workbook for grades 7-9 pupils, Bellville, South Africa: University of the Western Cape.

Struthers, P. (2012), "Universities working with schools: health promoting schools, HIV and TB", HIV and Education Symposium, University of the Western Cape $\quad(U W C) . \quad$ Online: http://www.hivaidsuwc.org.za/docs/Struthers_HIV and_Education_Symposium_March2012. pdf. [Retrieved 15 January 2013].

Thrift, N. (1999), "The Place of Complexity", Theory, Culture \& Society, Vol. 16 No. 3, pp. 31-69. 
University of the Western Cape (UWC). (2010), "Centre for Research in HIV and AIDS”, Human Capacity Development to Address HIV/AIDS in South Africa.

Online

http://www.hivaidsuwc.org.za/index.php?option $=$ com content\&view=article\&id=31:cdcbreakdown\&catid $=4$. [Retrieved 15 January 2013]

University of the Western Cape (UWC). (2012), "Health Promoting School (HPS) Project, TB and HIV/AIDS”, Newsletter April 2012. Online: http://174.132.194.250/ health/wp-content/uploads/2012/09/HPS-

Project-Newsletter-3-April-2012-Y3 4.pdf. [Retrieved 15 January 2013 ].

Western Cape Education Department. (2011), Western Cape Education Department releases 2010 Literacy and Numeracy Results. Online: http://www.capegateway.gov.za/eng/your gov/3572/news/2011/feb/21353 8. [Retrieved 12 May, 2011].

World Health Organisation. (1986), The Ottawa Charter for Health Promotion. Online:

http://www.who.int/healthpromotion/conferences/previous/ottawa/en/ind ex.html. [Retrieved 9 September, 2013].

Young, I. (2005), "Editorial. Health promotion in schools-a historical perspective", Promotion \& Education, Vol. 12 No. 3-4, pp. 111-117.

\footnotetext{
'The term 'coloured' is used in South Africa to describe a population group that comprises people from mixed-race origin descending from the intermarriage of white settlers, African natives, and Asian slaves who were brought to South Africa from the Dutch colonies in the eighteenth and nineteenth centuries. Statistics South Africa continues to classify people "by population group, in order to monitor progress in moving away from the apartheid-based discrimination of the past. However membership of a population group is now based on self-perception and self-classification, not on a legal definition" (Statistics South Africa 2003).
} 